\title{
Development and application of a tool to measure hearing health literacy of young people in the Islamic Republic of Iran
}

Saeid Mahmoudian, ${ }^{1,2}$ Mohammad Farhadi, ${ }^{1,2}$ Alireza Mahdavi Hezaveh, ${ }^{3}$ Mostafa Maleki, ${ }^{4}$ Sedigheh Shariatinia ${ }^{5}$ and Mohsen Shams ${ }^{6}$

${ }^{1}$ Ear, Nose and Throat, and Head and Neck Research Centre, Hazrat Rasoul Akram Hospital, The Five Senses Institute, Iran University of Medical Sciences, Tehran, Islamic Republic of Iran. ${ }^{2}$ WHO Collaborating Centre for Research and Education on Hearing Loss, Iran University of Medical Sciences, Tehran, Islamic Republic of Iran. ${ }^{3}$ Noncommunicable Diseases Control Centre, Ministry of Health and Medical Education, Tehran, Islamic Republic of Iran. ${ }^{4}$ School of Public Health, Tehran University of Medical Sciences, Tehran, Islamic Republic of Iran. ${ }^{5}$ School of Public Health, Isfahan University of Medical Sciences, Isfahan, Islamic Republic of Iran. ${ }^{6}$ School of Health, Yasuj University of Medical Sciences, Yasuj, Islamic Republic of Iran. (Correspondence to: Mohsen Shams: moshaisf@yahoo.com).

\begin{abstract}
Background: A reliable and valid tool to assess hearing health literacy in Iranian young people is lacking.

Aims: This study aimed to develop a tool to assess the hearing health literacy of young people in the Islamic Republic of Iran and to use the tool to determine the hearing health literacy of a sample of Iranians aged 12-25 years.

Methods: A questionnaire was designed with three skill sections: obtaining health information, evaluating this information and applying it to benefit health. The validity and reliability of the tool were determined. Cluster sampling was used to select 50 urban clusters across the country from which 5000 Iranians aged between 12-25 years old were selected to complete the questionnaire.
\end{abstract}

Results: The final questionnaire had 22 items with scores ranging from 22 to 44 . The Cronbach alpha was 0.65 , and content validity ratio and index were 0.92 and 0.82 , respectively. Of the 5000 questionnaires completed, 4890 were included in the analysis. The mean (standard deviation (SD)) age of the participants was 17 (SD 3) years and $45.9 \%$ were males. The mean score on the tool was 30.81 (SD 3.75), indicating inadequate health literacy (score 22-36). Only 137 (2.8\%) participants had adequate health literacy (score 37-44). Statistically significant differences in mean hearing health literacy were seen for sex, age, years of education, occupation, marital status and income $(P<0.05)$.

Conclusions: Given the low level of hearing health literacy in Iranian young people, programmes to improve the ear and hearing health literacy are urgently needed.

Keywords: adolescent, young adult, health literacy, hearing, Iran

Citation: Mahmoudian S; Farhadi M; Mahdavi Hezaveh A; Maleki M; Shariatinia S; Shams M. Development and application of a tool to measure hearing health literacy of young people in the Islamic Republic of Iran. East Mediterr Health J. 2021;27(2):177-182. https://doi.org/10.26719/emhj.20.106

Received: 19/05/19; accepted: 10/02/20

Copyright (C) World Health Organization (WHO) 2021. Open Access. Some rights reserved. This work is available under the CC BY-NC-SA 3.0 IGO license (https://creativecommons.org/licenses/by-nc-sa/3.o/igo)

\section{Introduction}

According to the World Health Organization (WHO), 466 million people worldwide have a debilitating hearing loss (1). The results of studies in the Islamic Republic of Iran also show that 13.5 per 1000 population suffer from hearing loss or deafness (2). Given that the prevalence of hearing impairment is higher in elderly people, these figures are expected to increase significantly in the future due to the ageing population of the world. Most people with debilitating hearing loss live in low- and middle-income countries like the Islamic Republic of Iran (3). According to WHO estimates, at least half of the worldwide deafness and hearing impairment can be avoided through prevention, early diagnosis and proper management (such as rapid treatment of ear infections, ear surgery, or hearing aids) (4).

Health literacy is defined as individuals' capacity to obtain, interpret and understand basic health information and services, and the ability to use the information and services in ways that improve health (5). Health literacy is a relatively new concept. Research has been done to better understand and measure health literacy which has led to the development of tools that investigate the health literacy status in individuals and groups. The Iranian Health Literacy Questionnaire and Iranian Adolescent Health Literacy Measurement Tool were developed to measure general health literacy, and the AIDS Literacy Questionnaire was designed to measure health literacy related to HIV/AIDS (6-8).

Healthy behaviour and habits are formed during the adolescence and youth (9). Measuring the health literacy of adolescents and young people about ears and hearing and promoting aural health can help to create healthy lifestyles in this group and reduce adverse consequences of low health literacy at the older ages in the future.

In recent years, the use of personal portable music player devices such as MP3 players, iPods and mobile telephones has become popular, especially among adolescents and young people. The long battery life, high storage capacity and high audio output quality of these devices allow users to listen to loud music for extended periods of time. However, the inappropriate use of music player devices has a harmful effect on hearing; for example, listening to music at an intensity of more than $50 \%$ of the device output per hour for at least 1 hour (10). 
Therefore, new approaches that maintain and improve ear and hearing health, and prevent and manage ear disease are needed.

Discrepancy between the content of education, information and communication programmes and the audience's capacity to understand such content is an important reason for failure of the health service delivery system (7,11). Therefore, increasing such capacity and tailoring plans to the capacity of the audience are ways to improve the effect of such programmes. Awareness of the health literacy level in the community is a necessity to both increase capacity and improve education, information and communication programmes. However, the existing health literacy tools are not appropriate for assessing ear and hearing health. Therefore, a tool needs to be developed and validated that can assess ear and hearing health literacy. This tool could then be used to evaluate the ear and hearing health literacy of adolescents and young adults in Iranian society. In this study, we aimed to: (i) develop and validate a tool to assess ear and hearing heath literacy in adolescents and young adults aged 12 to 25 years in the Islamic Republic of Iran, (ii) use the tool to evaluate ear and hearing heath literacy of this age group and.

\section{Methods}

\section{Study design}

The study had two parts: (i) development and validation of a tool to assess ear and hearing health literacy and (ii) use of the tool in a cross-sectional study to measure the ear and hearing health literacy of Iranian adolescents and young people aged 12-25 years. The study was carried out between May 2017 and June 2018.

\section{Tool development and validation}

We conducted a literature search and review of all available printed and electronic material on ear and hearing health in the Islamic Republic of Iran including guidelines for health care providers and material disseminated for the general population, especially adolescents. We searched for materials in Farsi and used keywords related to ear and hearing health, and adolescence. We also searched relevant databases of the Ministry of Health and Medical Education, Iranian universities of medical sciences and related organizations, such as ear and hearing research centres and websites. Two of our team of researchers did the search and selected the materials. The manager of the research team made the final decision about the appropriate materials to include. After this, the same two researchers extracted the data and and classified them into three groups: disease prevention, care and treatment, and health promotion. From the extracted data, a number of questions were drafted, from which experts selected 24 questions based on the general framework of the test of functional health literacy in adults (TOFHLA) tool and according to three skill sections: searching for and obtaining health information, understanding and evaluating this information, and ap- plying this information to benefit health (12). We sought the opinions of a panel of experts in ear and hearing health about the items and general framework of the tool through two sessions, and the tool was modified accordingly. We sent the revised version to other experts in otolaryngology disease, epidemiology, health education and promotion, and social medicine to determine the index and content validity ratio of the tool. Based on these two steps, two items were removed and others were modified to provide a draft version for reliability testing.

We used the Cronbach alpha to measure internal consistency; we gave the tool to 527 young adults and adolescents to complete to evaluate its reliability using the split half method. We also did a factor analysis to determine the relationship of items with each other and the main concepts. The final tool for ear and hearing health literacy was in Farsi and had 22 multiplechoice item. It had a Cronbach alpha value of 0.65 , and content validity ratio and content validity index of 0.92 and 0.82 , respectively. The tool had three sections: and searching obtaining health information (two questions), understanding and evaluating information (15 questions), and applying information (5 questions). In the data analysis, correct answers were scored 2 and wrong answers scored 1 ; thus the score range was 22-44.

\section{Evaluating health literacy}

We used the validated tool to assess ear and hearing health literacy in Iranian adolescents and young people aged $12-25$ years.

We selected the sample through cluster sampling. We determined the study sample size based on the formula for cross-sectional studies and the results of a previous study on health literacy in Iranian adolescents (13). We assumed an alpha error of 0.05 , estimated accuracy of 0.5 and significance level of 0.05 . The initial sample size needed was determine to be 4000 . According to the cluster sampling method and a design effect of 1.5 , the final sample size was 5000 respondents.

We considered the urban regions of the Islamic Republic of Iran as the cluster units, and used the 2011 population census (14) as the sampling framework of cities. After listing all cities in the country, we randomly selected 50 cities from all the country as the final clusters. In each cluster, 100 questionnaires were completed. We selected the home closest to the health centre in the town centre as the starting point of each cluster. If the household had a person aged 12-25 years old, then the interviewer asked him/her to participate in the study. If the household did not have a member in that age group or if the person declined to participate, the interviewer went to the next home. If the household had more than one member in the age group, only one was invited to complete the questionnaire. The interviewer then moved anticlockwise from the home visited, leaving 10 homes in between, to the next selected home until 100 participants had been included. In the case of complexes with several apartments, the interviewer went to the first apartment, 
then skipped the next 10 and the apartment after this was included.

In order to coordinate completion of questionnaires at the national level, we held a session at the headquarters of the health deputy of Iranian Ministry of Health and Medical Education, with the participation of managers in department of noncommunicable diseases at universities of medical sciences. In this session, the main project implementer (corresponding author) presented the tool and provided training on how to complete it for provincial and county level implementers so that they could then train their own interviewers.

The trained interviewers oversaw the completion of 5000 questionnaires between October and November 2017. The inclusion criteria of the responders were: agreement to participate in the study by completing and signing the consent form, age 12-25 years old, absence of hearing loss or ear/hearing disorders, and adequate literacy to complete the questionnaire. In our analysis, an incomplete questionnaire was the main exclusion criteria.
We categorized the participants into two groups: inadequate health literacy (health literacy score of 22-36) and those with adequate health literacy (health literacy score of 37-44).

We used SPSS version 18 to analyse the data and took account of the cluster sampling method used. We present the data as mean and standard deviation (SD), and relative frequency (number and percentage). We compared data using the independent t-test and ANOVA.

\section{Ethical considerations}

The Department of the Ear Disease, Ministry of Health of Medical Education approved the study. The interviewers explained the purpose of the study and that participation was voluntary. Those who agreed to participate signed a consent form. Participants were assured that their information would remain confidential.

\section{Results}

In total, 5555 participates were approached and 5000 agreed to participate, a response rate of $90 \%$. We exclud-

\begin{tabular}{|c|c|c|c|c|}
\hline \multirow[t]{2}{*}{ Variable } & $\begin{array}{c}\text { Total } \\
(n=4890)\end{array}$ & $\begin{array}{l}\text { Adequate health literacy } \\
\text { (score 37-44) }\end{array}$ & $\begin{array}{l}\text { Total health } \\
\text { literacy }\end{array}$ & $P$-value \\
\hline & No. (\%) & No. (\%) & Mean score (SD) & \\
\hline \multicolumn{5}{|l|}{ Age (years) } \\
\hline $12-18$ & $3383(69.4)$ & $89(2.6)$ & $30.72(3.75)$ & \multirow[t]{2}{*}{$0.01^{\mathrm{a}}$} \\
\hline $19-25$ & $1490(30.6)$ & $51(3.4)$ & $31.01(3.74)$ & \\
\hline \multicolumn{5}{|l|}{ Sex } \\
\hline Male & $2221(45.9)$ & $51(2.3)$ & $30.41(3.84)$ & \multirow[t]{2}{*}{$<0.001^{\mathrm{a}}$} \\
\hline Female & $2619(54.1)$ & $83(3.2)$ & $31.13(3.64)$ & \\
\hline \multicolumn{5}{|l|}{ Years of education } \\
\hline $1-12$ & $4342(88.8)$ & $113(2.6)$ & $31.65(3.70)$ & \multirow[t]{2}{*}{$<0.001^{\mathrm{a}}$} \\
\hline$>12$ & $547(11.2)$ & $25(4.6)$ & $30.7(3.74)$ & \\
\hline \multicolumn{5}{|l|}{ Occupation } \\
\hline Employed & $309(6.4)$ & $17(5.5)$ & $31.75(4.04)$ & \multirow[t]{5}{*}{$<0.001^{b}$} \\
\hline Student & $3589(74.5)$ & $100(2.8)$ & $30.79(3.75)$ & \\
\hline Housewife & $553(11.5)$ & $10(1.8)$ & $30.73(3.50)$ & \\
\hline Unemployed & $331(6.9)$ & $12(3.6)$ & $30.66(3.70)$ & \\
\hline Other & $33(0.7)$ & $1(3.0)$ & $30.39(3.45)$ & \\
\hline \multicolumn{5}{|l|}{ Marital status } \\
\hline Single & $4019(82.9)$ & $112(2.8)$ & $30.79(3.76)$ & \multirow[t]{3}{*}{$0.03^{\mathrm{b}}$} \\
\hline Married & $816(16.8)$ & $23(2.8)$ & $30.99(3.62)$ & \\
\hline Divorced/separated & $15(0.3)$ & $\mathrm{o}(0.0)$ & $28.67(3.88)$ & \\
\hline \multicolumn{5}{|l|}{ Monthly income (US\$) } \\
\hline$<100$ & $2428(51.2)$ & $53(2.2)$ & $30.45(3.74)$ & \multirow[t]{5}{*}{$<0.001^{b}$} \\
\hline $100-200$ & $1761(37.1)$ & $65(3.7)$ & $31.22(3.73)$ & \\
\hline $200-300$ & $375(7.9)$ & $10(2.7)$ & $31.07(3.75)$ & \\
\hline $300-400$ & $91(1.9)$ & $1(1.1)$ & $31.36(3.36)$ & \\
\hline$>400$ & $88(1.9)$ & $3(3.4)$ & $31.53(3.81)$ & \\
\hline
\end{tabular}


ed 110 questionnaires because they were incomplete; thus 4890 questionnaires were included in the analysis.

Of the 4890 participants in the study, 50 did not record their sex and 2221/4840 (45.9\%) were males. The mean (SD) age of the participants was 17 (SD 3) years and mean years of education were 9 (SD 2) years. Table 1 gives the demographic data of the participants.

The mean (SD) score on the ear and hearing health literacy tool was 30.81 (SD 3.75) (Table 2). According to our classification of scores, this score shows our participants had inadequate ear and hearing health literacy (score of 22-36). Table 2 shows the scores of the three parts of the tool (searching for, understanding and applying health information). Only 137 (2.8\%) participants had adequate health literacy (score 37-44) and 4753 (97.2\%) had inadequate health literacy.

Of 3383 participants in the age group 12-18 years, only $89(2.6 \%)$ had adequate ear and hearing health literacy. Only 51 of 1490 (3.4\%) participants in the age group 1925 years had adequate ear and hearing health literacy (Table 1). There was a statistically significant difference in the mean ear and hearing health literacy scores between these two age groups $(P=0.01)$. Similarly, the mean score for health literacy of participants with an education of more than 12 years was significantly higher than that of participants with $1-12$ years of education $(P<0.01)$. A greater proportion of women $(3.2 \%)$ had adequate health literacy than men $(2.3 \%)$ and women had a significantly higher mean score for health literacy than men $(P<0.001)$; 31.13 (SD 3.64) versus 30.41 (SD 3.84). However, both these scores indicated inadequate health literacy. Statistically significant differences in mean ear and hearing literacy were seen for occupation $(P<0.001)$, marital status $(P=$ $0.03)$ and income $(P<0.001)$. However, in all cases the mean scores indicated inadequate ear and hearing health literacy in all categories within the variable (Table 1)

\section{Discussion}

Overall ear and hearing health literacy among Iranian adolescents and young people is low. Only about 3\% of the participants had an adequate health literacy. In addition, their skills of searching for health information, understanding and evaluating this information, and using such information are limited. Given the relationship between health literacy and health that has been shown

Table 2 Mean scores and range for total ear and hearing health literacy and its three components

\begin{tabular}{lcc}
\hline Health literacy & $\begin{array}{c}\text { Mean } \\
\text { (standard deviation) }\end{array}$ & Range \\
\hline $\begin{array}{l}\text { Searching and obtaining } \\
\text { information }\end{array}$ & $2.76(0.61)$ & $2-4$ \\
$\begin{array}{l}\text { Understanding and } \\
\text { interpreting information }\end{array}$ & $20.95(2.81)$ & $15-30$ \\
Using information & $7.10(1.33)$ & $5-10$ \\
Total health literacy & $30.81(3.75)$ & $22-44$ \\
\hline
\end{tabular}

in other studies (13), ear and hearing health in young Iranians (12-25 years) is at risk. These findings support the inclusion of ear and hearing health in the Iranian health services system and effective measures should be taken to prevent it. In addition, appropriate interventions should be designed and implemented to improve the ear and hearing health literacy of Iranian young people.

Broadly speaking, based on the general and specific studies on health literacy, most Iranians have inadequate health literacy. The national study on general health literacy of Iranian adults living in cities showed that half of the participants had inadequate health literacy (15). Consistent with our study, $54.6 \%$ and $41.1 \%$ of pregnant women in Tehran and Minab health centres had inadequate or borderline health literacy $(16,17)$. Another study on students' health literacy at Farhangian University reported that $44.9 \%$ of students had inadequate health literacy (18). A health literacy survey of 400 adults in Balochistan region also found that $86 \%$ of respondents had inadequate health literacy (19). Furthermore, research on health literacy in specific health fields indicate a similar situation. In a health literacy study on HIV/AIDS in adults in Yasuj, 83.6\% of the people had inadequate health literacy (11). This finding is similar to our results. In a study on oral and dental health literacy, $47 \%$ of people in Isfahan and 60\% in Tehran had inadequate oral and dental health literacy $(20,21)$. Despite the fact that all of our participants were students and were literate, the results of our study also indicate that Iranian adolescents and young people had an inadequate ear and hearingrelated health literacy.

Our results indicate that the following groups had poorer ear and hearing health literacy: younger age group, participants with fewer years of education, and men. Therefore, these groups should be given higher priority to receive interventions aiming to improve ear and hearing health literacy in different regions of the Islamic Republic of Iran. Most studies in the country indicate that vulnerable groups such as those with less education and lower income, and housewives and unemployed people have inadequate and limited health literacy $(20,22)$.

Our results also show that the participants had low skill levels in all areas of health literacy - searching and obtaining, understanding and evaluating, and applying ear and hearing health literacy information. This finding indicates the need to take account of all aspects of health literacy when developing effective interventions to improve ear and hearing health literacy in young Iranians.

Our study is the first in the Islamic Republic of Iran that developed an assessment tool for ear and hearing health literacy. The tool considered spoken, written and visual content on ear and hearing health that individuals might face in their daily lives. Therefore, we hope that the use of this tool could help improve the spoken and written communication between health care providers and people referred to centres for ear and hearing services, and allow health messages on ear and hearing to be clearly communicated and understood. Unlike other 
Iranian health literacy studies, which used general health literacy tools, we developed and used a specific ear and hearing health tool. In addition to these strengths, our study has two main limitations. First, as we developed a health literacy tool specifically for ear and hearing health for Iranian young people, there were no similar tools for comparison. Second, our tool had a greater focus on measuring health literacy associated with noise-induced hearing impairment. However, ear and hearing health can include other dimensions such as genetic and congenital factors, and cure for diseases, which were not included in our tool.

Funding: The Center for Noncommunicable Diseases Control and Prevention, Ministry of Health and Medical Education, and Ear, Nose and Throat and Head and Neck Research Center, Iran University of Medical Sciences (MT/30/12069) supported this work.

Competing interests: None declared.

\section{Mise au point et application d'un outil destiné à mesurer les connaissances en santé auditive des jeunes en République islamique d'Iran}

\section{Résumé}

Contexte : Il n'existe pas d'outil fiable et valable pour évaluer les connaissances en matière de santé auditive des jeunes Iraniens.

Objectifs : La présente étude avait pour objectif de mettre au point un outil permettant d'évaluer les connaissances en matière de santé auditive des jeunes en République islamique d'Iran et d'utiliser cet outil pour déterminer ces connaissances dans un échantillon d'Iraniens âgés de 12 à 25 ans.

Méthodes : Un questionnaire a été conçu avec trois sections de compétences : obtenir des informations sur la santé, évaluer ces informations et les appliquer pour améliorer la santé. La validité et la fiabilité de l'outil ont été déterminées. Un échantillonnage en grappes a été utilisé pour sélectionner 50 grappes urbaines à travers le pays parmi lesquelles 500 Iraniens âgés de 12 à 25 ans ont été choisis pour remplir le questionnaire.

Résultats : Le questionnaire final comportait 22 items avec des scores compris entre 22 et 44 . Lalpha de Cronbach était de 0,65 ; le ratio et l'indice de validité du contenu étaient respectivement de 0,92 et 0,82. Sur les 5000 questionnaires remplis, 4890 ont été inclus dans l'analyse. Lâge moyen (écart type (ET)) des participants était de 17 ans (ET 3) et 45,9 \% étaient des hommes. Le score moyen pour l'outil était de 30,81 (ET 3,75), signe d'une littératie en santé insuffisante (score 22 à 36). Seuls 137 (2,8 \%) des participants possédaient une littératie en santé adéquate (score 37-44). Des différences statistiquement significatives dans les connaissances moyennes en matière de santé auditive ont été observées eu égard au sexe, à l'âge, aux années d'études, à la profession, au statut marital et aux revenus ( $\mathrm{p}<0,05)$.

Conclusions : Étant donné le faible niveau de connaissances en santé auditive des jeunes Iraniens, des programmes visant à améliorer ce domaine sont nécessaires de toute urgence.

$$
\begin{aligned}
& \text { إعداد واستخدام أداة لقياس مدى الوعي بصحة السمع في صفوف الشباب بجمهورية إيران الإسلامية } \\
& \text { سعيد محموديان، سعيد فرهدي، علي رضا هضاوه، مصطفى مالكي، صديقة شريعتنيا، محسن شمس ، }
\end{aligned}
$$

$$
\text { الخلفية: لا تتوافر أداة موثوقة وصالحة لتقييم الوعي بصحة السمع في صفوف الشباب الإيراني. }
$$

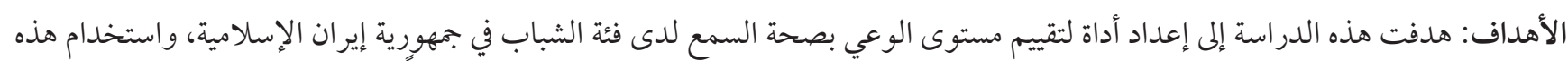

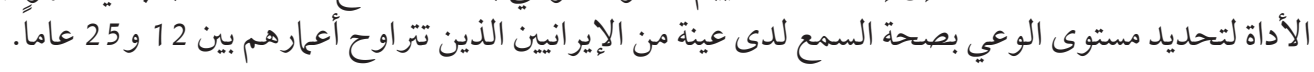

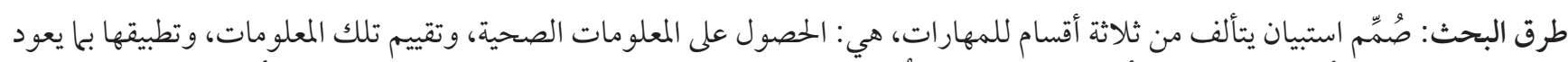

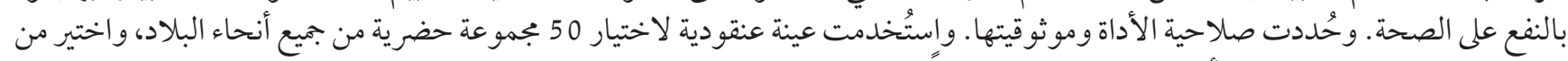

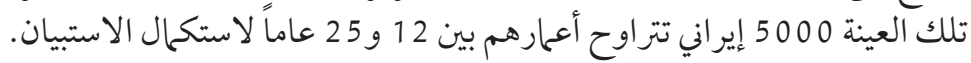

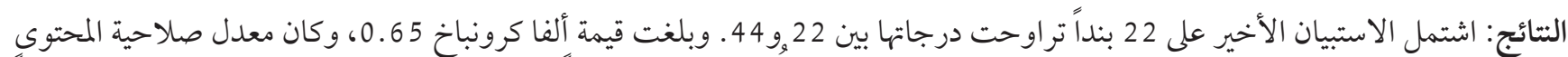

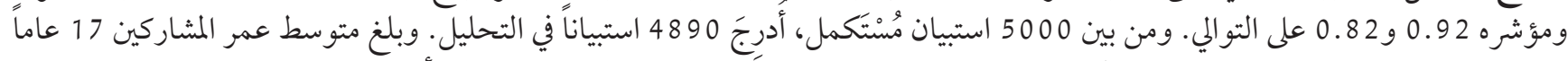

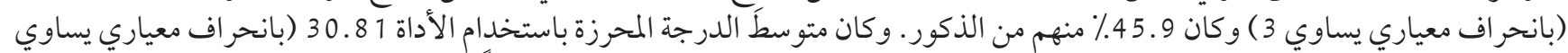

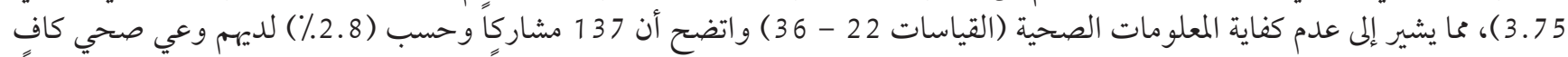

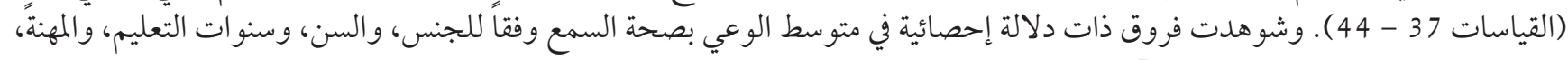
والحالة الاجتناعية، والدخل (4) ( 
الاستنتاجات: بالنظر إلى انخفاض مستوى الوعي بصحة السمع في صفوف الشباب الإيراني، فهناك حاجة ماسة إلى وضع برامج لتحسين الوعي بصحة الأذن و السمع.

\section{References}

1. Deafness and hearing loss. Geneva: World Health Organization; 2020 (Fact sheet; https://www.who.int/en/news-room/factsheets/detail/deafness-and-hearing-loss, accessed 21 May 2020).

2. Moradi G, Mostafavi F, Hajizadeh M, Amerzade M, Bolbanabad AM, Alinia C, et al. Socioeconomic inequalities in different types of disabilities in Iran. Iran J Public Health. 2018;47(3):427-34.

3. Chauhan RC, Mishra AK, Kandan M, Singh Z. Self-reported hearing impairment among rural adult population of coastal Tamil Nadu. Int J Otorhinolaryngology Head Neck Surg. 2015;1(1):23-6. http://doi.org/10.18203/issn.2454-5929.ijohns20150582

4. Primary ear and hearing care training resource. Geneva: World Health Organization; 2006. https://www.who.int/pbd/deafness/ activities/hearing_care/en/

5. $\quad$ Bedworth D, Bedworth AE. Dictionary of health education. Oxford: Oxford University Press; 2009.

6. Montazeri A, Tavousi M, Rakhshani F, Azin SA, Jahangiri K, Ebadi M, et al. [Health Literacy for Iranian Adults (HELIA): development and psychometric properties]. Payesh. 2014;13(5):589-99. (in Farsi)

7. Ghanbari S, Ramezankhani A, Mehrabi Y, Montazeri A. [The health literacy measure for adolescents (HELMA): development and psychometric evaluation.] Payesh (Health Monitor). 2016;15(4):404-10. (in Farsi)

8. Shams M, Karimzadeh Shirazi K, Fararouei M, Shariatinia S. [Developing a tool for measuring HIV/AIDS literacy for Iranian society.] J Ilam Univ Med Sci. 2016;24(5):138-50. (in Farsi)

9. Frech A. Healthy behavior trajectories between adolescence and young adulthood. Advances in life course research. 2012;17(2):59-68. https://doi.org/10.1016/j.alcr.2012.01.003

10. Sharifian Alborzi M, Naderi S, Jafari Z, Tabatabai SM. [The effect of listening to music on young personal listening device users]. J Rehab Med. 2015;4(4):80-8. (in Farsi)

11. Shariatinia S, Fararoei M, Karimzadeh Shirazi K, Shams M. [Assessment of HIV/AIDS literacy in 15-49-year-old people in Yasuj and its related factors.] Armaghane Danesh. 2015;19(12):1082-95. (in Farsi)

12. Parker RM, Baker DW, Williams MV, Nurss JR. The test of functional health literacy in adults. J Gen Intern Med. 1995;10(10):537-41. https://doi.org/10.1007/BF02640361

13. Saeedy Golluche F, Jalili Z, Tavakoli R. [Study of the relationship between health literacy and nutritional practice in high school adolescents in Tehran]. Iran J Health Educ Health Promot. 20175;5(3):224-30. (in Farsi)

14. [General population and housing census, 1390.] Tehran: Statistical Center of Iran; 2011 (https://www.amar.org.ir/Portals/o/Files/ abstract/1390/sarshomarigo_nahaii.pdf, accessed 21 July 2020) (in Farsi).

15. Tavousi M, Haeri MA, Rafiefar S, Solimanian A, Sarbandi F, Ardestani M, et al. [Health literacy in Iran: findings from a national study.] Payesh. 2016;15(1):95-102. (in Farsi)

16. Zaree F, Karimi F, Mohseni S, Mdani S, Dadipoor S, Mdani AH. [Health literacy of pregnant women and some related factors in pregnant women referred to Minab health centers]. J Preve Med. 2017;4(2):40-6. (in Farsi)

17. Ghanbari S, Majlessi F, Ghaffari M, Mahmoodi Majdabadi M. [Evaluation of health literacy of pregnant women in urban health centers of Shahid Beheshti Medical University.] Daneshvar Med. 2012;19(97):1-12. (in Farsi)

18. Ahmadi FZ, Mehrmohammadi M, Talaee E, Fardanesh H, Paknahad M, Taghizadeh S, et al. [Health literacy among students of Farhangian University.] Payesh. 2018;17(3):257-66. (in Farsi)

19. Izadirad H, Zareban I. [The relationship of health literacy with health status, preventive behaviors and health services utilization in Baluchistan, Iran.] J Educ Community Health. 2015;2(3):43-50. (in Farsi)

20. Sistani M, Yazdani R, Virtanen J, Pakdaman A, Murtomaa H. Oral health literacy and information sources among adults in Tehran, Iran. Community Dent Health. 2013;30(3):178-82. https://doi.org/10.1922/CDH_3159Yazdanio5

21. Saied MZ, HaghighiI M. [Assessing oral health literacy among the residents' students of Isfahan, 2014-2015.] J Isfahan Dent Sch. 2016;12(3):268-79. (in Farsi)

22. Naderi M, Rajati F, Yusefi H, Tajmiri M, Mohebi S. [Health literacy among adults of Isfahan, Iran.] J Health System Res. 2013;9(5):473-83. (in Farsi) 